\title{
Serangan Tribolium castaneum pada Beras di Penyimpanan dan Pengaruhnya terhadap Serangan Cendawan dan Susut Bobot
}

\section{Tribolium castaneum Infestation in Stored Milled Rice and Its Effect on Fungal Infection and Weight Loss}

\author{
Okky Setyawati Dharmaputra ${ }^{1,3 *}$, Hariyadi Halid ${ }^{2}$ Sunjaya $^{3}$ \\ ${ }^{1}$ Institut Pertanian Bogor, Bogor 16680 \\ ${ }^{2}$ Perusahaan Umum BULOG, Jakarta 12950 \\ ${ }^{3}$ SEAMEO BIOTROP, Bogor 16134
}

\begin{abstract}
ABSTRAK
Tribolium castaneum merupakan serangga hama penting pada penyimpanan beras di Indonesia. Penelitian ini bertujuan menguji perbedaan jumlah pasangan T. castaneum terhadap spesies dan populasi cendawan pascapanen pada beras selama penyimpanan dan pengaruhnya terhadap kadar air dan susut bobot beras. Beras ditempatkan di dalam stoples ( $250 \mathrm{~g} /$ stoples) dan diinfestasi dengan 5,10 , dan 20 pasang T. castaneum. Sebagai kontrol, stoples hanya berisi beras. Setiap perlakuan (termasuk kontrol) dibuat tiga ulangan. Penyimpanan dilakukan selama 1, 2, dan 3 bulan pada kondisi laboratorium. Kadar air (berdasarkan bobot basah) ditentukan menggunakan metode oven. Isolasi cendawan dilakukan dengan metode pengenceran yang dilanjutkan dengan metode cawan tuang pada medium Dichloran 18\% glycerol agar. Susut bobot (berdasarkan bobot kering) beras ditentukan setelah 3 bulan penyimpanan. Hasil penelitian menunjukkan bahwa populasi imago T. castaneum semakin meningkat dengan bertambahnya jumlah pasangan $T$. castaneum yang diinfestasikan dan lama penyimpanan. Kadar air beras relatif konstan selama penyimpanan dan diduga lebih banyak dipengaruhi oleh kondisi lingkungan daripada keberadaan T. castaneum. Sebanyak 19 spesies cendawan telah diisolasi selama penyimpanan. Cendawan yang dominan ialah Aspergillus flavus dan Penicillium citrinum. Populasi total cendawan semakin menurun setelah 2 dan 3 bulan penyimpanan dengan bertambahnya jumlah pasangan $T$. castaneum yang diinfestasikan. Susut bobot semakin meningkat dengan bertambahnya jumlah pasangan $T$. castaneum yang diinfestasikan. Berdasarkan susut bobot beras, penyimpanan yang paling baik ialah pada jumlah pasangan $T$. castaneum adalah lima pasang, baik beras disimpan selama 1,2 , atau 3 bulan penyimpanan.
\end{abstract}

Kata kunci: Aspergillus flavus, cendawan pascapanen, kadar air, Penicillium citrinum, susut bobot

\begin{abstract}
Tribolium castaneum is an important insect pest of stored milled rice in Indonesia. The effect of $T$. castaneum on fungal infection of stored milled rice was investigated together with moisture content and weight loss. Milled rice were placed in glass jars ( $250 \mathrm{~g} / \mathrm{jar})$ and infested with 5, 10, and 20 pairs of $T$. castaneum. As control, the jars contained only milled rice. Three replications were made for each treatment (including the control). The jars were stored in storage room for 1, 2, and 3 months. Moisture contents (based on wet weight) of milled rice were determined using the oven method. Fungi were isolated and enumerated using dilution plating, followed by pour plate method on Dichloran $18 \%$ Glycerol Agar (DG18). Weight loss (based on dry weight) was determined after 3 months of storage. The results
\end{abstract}

*Alamat penulis korespondensi: Departemen Biologi, Fakultas Matematika dan Ilmu Pengetahuan Alam, Institut Pertanian Bogor, Jalan Agatis, Kampus Dramaga, Bogor 16680 Tel: 0251-8622833, Faks: 0251-8622833, Surel: okky@biotrop.org 
showed, that the population of adult $T$. castaneum increased with the increase in the number of pairs of infested $T$. castaneum and storage duration. The moisture contents of milled rice were relatively constant during storage. It was assumed, that the moisture contents were more influenced by the environmental conditions rather than the occurrence of T. castaneum. Nineteen fungal species were isolated Aspergillus flavus and Penicillium citrinum were the dominant fungal species. Total fungal population decreased after 2 and 3 months of storage, with the increase in the number of pairs of infested T. castaneum. Weight loss increased with the increase in the number of pairs of infested T. castaneum. Based on weight loss of milled rice, the best storage duration was found when the number of pairs of T. castaneum was five pairs, the duration of storage was 1,2 or 3 months of storage.

Key words : Aspergillus flavus, moisture content, Penicillium citrinum, postharvest fungi, weight loss

\section{PENDAHULUAN}

Beras adalah bagian bulir padi (gabah) yang telah dipisahkan dari sekam. Selama penyimpanan beras dapat mengalami penyusutan (kerusakan) dalam kualitas maupun kuantitasnya. Hal ini disebabkan antara lain oleh faktor biologi (serangga, cendawan, tikus, dan burung). Serangga dan cendawan masingmasing merupakan penyebab pertama dan ke-2 kerusakan. Serangan cendawan pada bijibijian yang disimpan dapat mengakibatkan perubahan warna, pemanasan, berbagai perubahan biokimia, produksi mikotoksin, dan susut bobot.

Laju perkembangan cendawan pascapanen pada biji-bijian dan tingkat kerusakan yang disebabkannya dapat dipengaruhi oleh keberadaan spesies dan populasi serangga pada biji-bijian tersebut. Serangga yang menginfestasi biji-bijian dapat membawa spora cendawan pada tubuhnya. Infestasi berat oleh serangga dapat mengakibatkan peningkatan kadar air dan pemanasan sehingga menstimulasi pertumbuhan cendawan (Wicklow 1995) .

Tribolium castaneum merupakan salah satu spesies serangga hama penting di penyimpanan di daerah tropik. Wiranata et al. (2013) melaporkan bahwa T. castaneum merupakan salah satu spesies serangga yang ditemukan pada beras di gudang Perusahaan Umum BULOG. Serangga tersebut mampu bertahan pada bahan pangan dengan kadar air rendah, terutama menimbulkan kerusakan pada serealia yang telah digiling, namun perkembangbiakannya tidak cepat pada serealia yang berkadar air rendah, masih utuh, dan bebas dari serpihan.

Penelitian ini bertujuan untuk mengetahui pengaruh $T$. castaneum terhadap spesies dan populasi cendawan pascapanen pada beras, serta pengaruhnya terhadap kadar air dan susut bobot beras selama penyimpanan.

\section{BAHAN DAN METODE}

\section{Penyimpanan Beras}

Beras yang berasal dari padi varietas IR64 dengan derajat sosoh $90 \%$, persentase butir patah $25 \%$, dan kadar air $\pm 13 \%$ ditempatkan di dalam stoples (250 g/ stoples). Selanjutnya stoples ditutup dengan kain batis dan disimpan selama 1, 2, dan 3 bulan pada kondisi laboratorium. Sebelum disimpan, beras difumigasi dengan fosfin (2 $\mathrm{g}$ ton $^{-1}$ beras) selama 6 hari. Fumigasi ditujukan untuk membunuh semua stadium serangga yang mungkin terdapat pada beras.

\section{Infestasi Tribollium castaneum}

Tribolium castaneum jantan dan betina dipisahkan pada stadium pupa serta dipelihara pada medium campuran terigu dan khamir dengan perbandingan 12:1 (Haines 1991). Pada umur antara 0-7 hari dari stadium imago, serangga dipindahkan pada beras selama 7 hari agar dapat beradaptasi dengan perubahan medium tersebut. Setelah itu T. castaneum dipisahkan dari beras dan didesinfeksi dengan natrium hipoklorit $0.6 \%$ selama 3 menit, kemudian dibilas 3 kali dengan akuades steril (Sinha dan Sinha 1992). Selanjutnya, 
serangga dimasukkan ke dalam setiap stoples yang berisi beras dengan 3 variasi pasangan, yaitu 5, 10, dan 20 pasang. Sebagai kontrol, beras tidak diinfestasi dengan $T$. castaneum. Setiap perlakuan dibuat 3 ulangan (3 stoples). Populasi T. castaneum dari masing-masing stoples untuk setiap perlakuan dihitung setelah 1, 2, dan 3 bulan penyimpanan.

\section{Pengambilan Sampel dan Cara Memperoleh Sampel Kerja}

Pengambilan sampel dilakukan sebelum penyimpanan, kemudian 1, 2, dan 3 bulan setelah penyimpanan dari setiap stoples. Serangga dipisahkan dari beras dengan menggunakan ayakan. Selanjutnya setiap sampel dibagi dengan pembagi sampel berbentuk boks guna mendapatkan sampel kerja untuk analisis kadar air dan analisis cendawan.

Penentuan Populasi Tribolium castaneum, Kadar Air, Cendawan Pascapanen, dan Susut Bobot

Populasi T. castaneum ditentukan dengan cara menghitung populasi imago dari setiap ulangan. Kadar air (berdasarkan bobot basah) ditentukan dengan menggunakan oven pada suhu $130{ }^{\circ} \mathrm{C}$ selama 2 jam (Chen 2003). Setiap ulangan dibuat 3 subulangan (5 $\mathrm{g}$ beras per sub ulangan).

Isolasi cendawan dilakukan dengan metode pengenceran berseri yang dilanjutkan dengan metode cawan tuang pada medium Dichloran $18 \%$ glycerol agar. Sebanyak $15 \mathrm{~g}$ beras yang telah digiling, dibuat suspensi dengan pengenceran $10^{-1}-10^{-5}$. Untuk setiap ulangan dibuat 2 subulangan $(2 \times 15 \mathrm{~g})$ dan untuk setiap pengenceran dilakukan 3 ulangan (3 cawan petri). Populasi setiap spesies cendawan per $\mathrm{g}$ beras per subulangan dihitung dengan cara menghitung rata-rata jumlah koloni setiap spesies cendawan dari 3 cawan petri dikalikan dengan faktor pengenceran yang memberikan koloni cendawan secara terpisah.

Cendawan diidentifikasi berdasarkan pada Pitt dan Hocking (2009). Susut bobot (berdasarkan bobot kering) ditentukan setelah 3 bulan penyimpanan, dengan rumus:

$$
\mathrm{SB}(\mathrm{Bk})=\mathrm{BAw}(\mathrm{Bk})-\mathrm{BAk}(\mathrm{Bk}) \text {, dengan }
$$

$\mathrm{SB}$, susut bobot; Bk, bobot kering; BAw, bobot awal; BAk, bobot akhir.

\section{Rancangan Percobaan}

Rancangan percobaan yang digunakan ialah rancangan acak lengkap yang disusun secara faktorial dengan 2 faktor. Faktor pertama ialah pemberian serangga yang terdiri atas 4 taraf, yaitu $0,5,10$, dan 20 pasang T. castaneum. Faktor kedua ialah lama penyimpanan yang terdiri atas 4 taraf, yaitu 0 , 1, 2, dan 3 bulan. Setiap perlakuan dibuat 3 ulangan. Untuk mengetahui pengaruh pemberian serangga terhadap populasi cendawan, digunakan rancangan acak kelompok dengan analisis kovarian karena pada awal penyimpanan, populasi total cendawan pada beras yang tidak diinfestasi dengan T. castaneum (kontrol), kemudian yang diinfestasi dengan 5, 10 dan 20 pasang T. castaneum adalah berbeda. Uji banding Duncan dilakukan jika terdapat pengaruh yang nyata terhadap salah satu faktor atau interaksi antarfaktor.

\section{HASIL}

\section{Populasi Tribolium castaneum}

Berdasarkan analisis ragam, jumlah pasangan $T$. castaneum, lama penyimpanan, dan interaksi antara keduanya menyebabkan perbedaan yang sangat nyata terhadap populasi serangga tersebut. Populasi T. castaneum semakin meningkat dengan meningkatnya jumlah pasangan $T$. castaneum yang diinfestasikan. Semakin lama waktu penyimpanan terutama setelah 2 bulan mengakibatkan semakin meningkatnya populasi $T$. castaneum. Setelah 1 dan 2 bulan penyimpanan populasi serangga (imago) tidak berbeda nyata, namun berbeda nyata dengan setelah 3 bulan penyimpanan. Populasi T. castaneum setelah satu bulan penyimpanan pada pemberian 5, 10, dan 20 pasang masing-masing adalah 10, 20, dan 40 ekor. Populasi tersebut sama dengan jumlah serangga yang diinfestasikan pada awal penyimpanan. Hal ini menunjukkan 
bahwa setelah 1 bulan penyimpanan belum terjadi pertambahan populasi (Tabel 1).

\section{Kadar Air}

Berdasarkan analisis ragam, tidak terdapat perbedaan yang nyata antara jumlah pasangan $T$. castaneum (termasuk kontrol) serta interaksi antarajumlah pasangan serangga dan lama penyimpanan terhadap kadar air beras, tetapi lama penyimpanan menunjukkan perbedaan yang sangat nyata. Kadar air beras selama 1, 2, dan 3 bulan penyimpanan tidak berbeda nyata, namun berbeda nyata dengan sebelum penyimpanan. Kadar air beras pada awal penyimpanan yaitu sekitar $13 \%$, sedangkan setelah penyimpanan kadar air beras sekitar 14\% (Tabel 2). Tampaknya kadar air beras tidak banyak dipengaruhi oleh T. castaneum yang diinfestasikan, melainkan lebih banyak dipengaruhi oleh kondisi lingkungan, yaitu suhu dan kelembapan relatif ruang simpan. Hal tersebut terlihat dari kadar air beras yang berbeda antara sebelum dan setelah penyimpanan, namun relatif konstan selama penyimpanan. Kisaran suhu dan kelembapan relatif ruang simpan juga relatif konstan selama penyimpanan.

\section{Spesies dan Populasi Total Cendawan Pascapanen}

Hasil isolasi cendawan selama penyimpanan, diperoleh 19 spesies cendawan yaitu Alternaria padwickii, Arthrinium sp., Aspergillus candidus, A. flavus, A. fumigatus, A. niger, A. penicillioides, A. restrictus, A. versicolor, $A$. wentii, Cladosporium cladosporioides, C. sphaerospermum, Mucor circinelloides, Endomyces fibuliger, Eurotium chevalieri, E. repens, Penicillium citrinum, $P$. herquei, dan Syncephalastrum racemosum. Cendawan yang dominan ialah $A$. flavus dan P. citrinum.

Empat dari 19 spesies cendawan yang diperoleh sebenarnya tergolong cendawan lapangan, yaitu A. padwickii, Arthrinium sp., C. cladosporioides, dan C. sphaerospermum. Spesies cendawan lainnya tergolong cendawan pascapanen.

Hasil analisis kovarian menunjukkan bahwa populasi total cendawan berbeda nyata antarjumlah pasangan T. castaneum (termasuk kontrol) setelah satu bulan penyimpanan, tetapi tidak berbeda nyata setelah 2 dan 3 bulan penyimpanan (Tabel 3). Dibandingkan dengan kontrol, setelah satu bulan penyimpanan

Tabel 1 Pengaruh pemberian pasangan Tribolium castaneum dan lama penyimpanan terhadap populasi imago Tribolium castaneum

\begin{tabular}{lccc}
\hline \multirow{2}{*}{$\begin{array}{l}\text { Lama penyimpanan } \\
\text { (bulan) }\end{array}$} & \multicolumn{3}{c}{ Pemberian Tribolium castaneum*(pasang) } \\
\cline { 2 - 4 } & 5 & 10 & 20 \\
\hline 1 & $10.00 \mathrm{a}$ & $20.00 \mathrm{a}$ & $40.00 \mathrm{ab}$ \\
2 & $25.00 \mathrm{a}$ & $33.67 \mathrm{ab}$ & $62.27 \mathrm{bc}$ \\
3 & $32.00 \mathrm{~cd}$ & $97.00 \mathrm{~d}$ & $186.67 \mathrm{e}$ \\
\hline
\end{tabular}

*Angka-angka yang diikuti huruf yang sama tidak berbeda nyata menurut uji banding Duncan pada taraf $\alpha 5 \%$

Tabel 2 Kisaran suhu dan kelembapan relatif ruang simpan selama penyimpanan dan pengaruh lama penyimpanan terhadap kadar air beras

\begin{tabular}{cccc}
\hline $\begin{array}{c}\text { Lama penyimpanan } \\
\text { (bulan) }\end{array}$ & $\begin{array}{c}\text { Suhu } \\
\left({ }^{\circ} \mathrm{C}\right)\end{array}$ & $\begin{array}{c}\text { Kelembapan relatif } \\
(\%)\end{array}$ & $\begin{array}{c}\text { Kadar air* } \\
(\% \text { bobot basah })\end{array}$ \\
\hline 0 & - & - & $13.12 \mathrm{a}$ \\
1 & $25.5-30.0$ & $63.3-89.7$ & $13.87 \mathrm{~b}$ \\
2 & $25.5-30.0$ & $62.7-89.7$ & $13.78 \mathrm{~b}$ \\
3 & $25.5-30.0$ & $61.3-89.7$ & $13.92 \mathrm{~b}$ \\
\hline
\end{tabular}

*Angka-angka yang diikuti huruf yang sama pada kolom yang sama tidak berbeda nyata menurut uji banding Duncan pada taraf $\alpha 5 \%$ 
populasi total cendawan meningkat pada pemberian $T$. castaneum sebanyak 5 pasang, namun menurun pada pemberian 10 pasang. Populasi total cendawan meningkat kembali pada pemberian 20 pasang, tetapi masih lebih rendah dibandingkan dengan pemberian 5 pasang T. castaneum. Setelah satu bulan penyimpanan, penurunan drastis populasi total cendawan pada pemberian 10 pasang selain disebabkan oleh serangga, diduga terjadi karena adanya antagonisme di antara cendawan.

Setelah 2 dan 3 bulan penyimpanan populasi total cendawan tidak berbeda nyata antar jumlah pasangan $T$. castaneum (termasuk kontrol). Meskipun demikian, populasi cendawan menurun dengan semakin bertambahnya jumlah pasangan serangga yang diinfestasikan.

\section{Susut Bobot}

Berdasarkan analisis ragam pemberian jumlah pasangan $T$. castaneum yang berbeda tidak memberikan pengaruh yang nyata terhadap susut bobot. Susut bobot pada kontrol dan pemberian 5,10 , dan 20 pasang T. castaneum setelah 3 bulan penyimpanan masing-masing ialah $0.34, \quad 1.39,2.35$, dan $3.59 \%$ tidak berbeda nyata menurut analisis ragam. Semakin meningkatnya susut bobot disebabkan oleh peningkatan populasi serangga dengan semakin lamanya penyimpanan dan semakin bertambahnya jumlah pasangan T. castaneum yang diinfestasikan.

\section{PEMBAHASAN}

Banyaknya butir retak dan rusak merupakan faktor penting yang menentukan keberhasilan T. castaneum dalam menyerang sorgum di penyimpanan (Utomo 2013. Siklus hidup $T$. castaneum relatif pendek sehingga laju peningkatan populasinya juga menjadi relatif cepat. Meskipun demikian, T. castaneum memiliki mekanisme khusus untuk membatasi jumlahnya. Umumnya $T$. castaneum membatasi populasinya melalui tingkah laku kanibalisme yang dilakukan oleh serangga dewasa (imago) dan larva (Flinn dan Campbell 2012). Kanibalisme lebih sering terjadi pada butir jagung yang masih utuh dibandingkan dengan pada butir retak atau yang berupa tepung karena larva lebih sulit memakan butir utuh.

Selain kanibalisme, perkembangan populasi serangga dalam penelitian ini dapat dipengaruhi oleh keberadaan cendawan. Menurut Davis (2013) serangga, tungau, dan cendawan menghasilkan zat volatil yang berbeda, yang bergabung dengan udara intergranular dalam ekosistem penyimpanan biji-bijian. Banyak dari zat volatil ini yang secara terpisah atau bersama-sama mempengaruhi tingkah laku, perkembangan, dan pertumbuhan populasi organisme hama dalam lingkungan atmosfer.

Kadar air biji-bijian dipengaruhi oleh kelembapan relatif, suhu, dan jenis komoditas. Kadar air memiliki pengaruh yang penting dalam menjaga kualitas beras selama penyimpanan karena peranannya

Tabel 3 Populasi total cendawan (koloni $\mathrm{g}^{-1}$ b.b.) pada beras selama penyimpanan yang diinfestasi dengan Tribolium castaneum

\begin{tabular}{lcccc}
\hline \multirow{2}{*}{$\begin{array}{l}\text { Jumlah pasangan } \\
\text { Tribolium castaneum }\end{array}$} & \multicolumn{5}{c}{$\begin{array}{c}\text { Populasi cendawan pada penyimpanan bulan ke- } \\
\text { (koloni g-1 bobot basah) }\end{array}$} \\
\cline { 2 - 5 } & 0 & 1 & 2 & \multicolumn{1}{c}{3} \\
\hline Kontrol & $136.67 \mathrm{~b}$ & $245.78 \mathrm{bc}$ & $258.79 \mathrm{a}$ & $136.56 \mathrm{~b}$ \\
5 & $100.33 \mathrm{a}$ & $291.47 \mathrm{c}$ & $140.28 \mathrm{a}$ & $128.34 \mathrm{~b}$ \\
10 & $138.67 \mathrm{~b}$ & $74.73 \mathrm{a}$ & $61.18 \mathrm{a}$ & $91.12 \mathrm{~b}$ \\
20 & $127.33 \mathrm{~b}$ & $127.80 \mathrm{ab}$ & $54.07 \mathrm{a}$ & $70.65 \mathrm{~b}$ \\
\hline
\end{tabular}

*Angka-angka yang diikuti huruf yang sama pada kolom yang sama, tidak berbeda nyata menurut uji banding Duncan dan lanjut analisis kovarian pada taraf $\alpha 5 \%$. 
dalam mengendalikan laju kerusakan bijibijian. Butir rusak menyerap lebih banyak air dibandingkan dengan butir utuh karena luas permukaannya lebih besar. Pada penelitian ini $T$. castaneum hanya mengakibatkan kerusakan fisik yang relatif kecil terhadap beras, yang ditunjukkan oleh susut bobot yang relatif rendah selama penyimpanan. Selain itu T. castaneum merupakan external feeder, sehingga tidak menyebabkan perubahan kadar air beras. Susut bobot yang relatif rendah pada beras setelah 3 bulan penyimpanan diduga karena $T$. castaneum tidak menyerang butir utuh, tetapi makan butir retak atau pecah, tanpa masuk ke bagian dalam butir (Sarwar 2013)

Penurunan populasi cendawan dengan semakin bertambahnya jumlah pasangan serangga yang diinfestasikan kemungkinan disebabkan oleh kuinon yang dihasilkan $T$. castaneum dan oleh aktivitas serangga tersebut dalam memakan cendawan. Pada penelitian ini populasi $T$. castaneum semakin meningkat dengan semakin lamanya waktu penyimpanan. Menurut Prendeville dan Stevens (2002) Tribolium dapat menghasilkan kuinon yang dapat menghambat mikrob. Peningkatan jumlah $T$. castaneum dalam sistem penyimpanan akan meningkatkan kuinon yang disekresikan oleh $T$. castaneum sehingga populasi cendawan akan menurun.

Pada pemberian 10 dan 20 pasang $T$. castaneum, penurunan populasi cendawan hanya terjadi setelah 2 bulan penyimpanan dan meningkat kembali setelah 3 bulan penyimpanan. Peningkatan kembali populasi cendawan diduga disebabkan oleh adanya penurunan aktivitas serangga dalam memakan cendawan dan produksi kuinon yang menurun, namun tingkat kerusakan yang disebabkan oleh serangga meningkat. Aktivitas T. castaneum dalam memakan beras menyebabkan cacat pada butiran beras sehingga cendawan lebih mudah berpenetrasi, sedangkan produksi kuinon yang rendah dapat disebabkan oleh terdapatnya serangga mutan.

Populasi total cendawan pada kontrol meningkat hingga 2 bulan setelah penyimpanan, tetapi menurun setelah 3 bulan penyimpanan. Diduga hal ini terjadi karena adanya antagonisme di antara cendawan; dari hasil isolasi setelah 3 bulan penyimpanan diperoleh $M$. circinelloides yang pertumbuhannya sangat cepat sehingga menghambat pertumbuhan cendawan lain.

Populasi imago $T$. castaneum pada beras semakin meningkat setelah 2 bulan penyimpanan dengan bertambahnya jumlah pasangan $T$. castaneum yang diinfestasikan. Kadar air beras relatif konstan selama penyimpanan dan diduga lebih banyak dipengaruhi oleh kondisi ruang simpan daripada keberadaan T. castaneum. Selama 3 bulan penyimpanan diperoleh 4 spesies cendawan lapangan dan 15 spesies cendawan pascapanen. Aspergillus flavus dan P. citrinum merupakan cendawan yang dominan. Populasi total cendawan pada beras semakin menurun setelah 2 dan 3 bulan penyimpanan, dengan bertambahnya jumlah pasangan T. castaneum yang diinfestasikan. Setelah 3 bulan penyimpanan, susut bobot semakin meningkat dengan bertambahnya jumlah pasangan $T$. castaneum yang diinfestasikan. Susut bobot paling rendah diperoleh apabila beras diinfestasi dengan 5 pasang $T$. castaneum selama penyimpanan 1, 2 dan 3 bulan penyimpanan.

\section{UCAPAN TERIMA KASIH}

Ucapan terima kasih penulis sampaikan kepada Rika Yuliarni dan teknisi Laboratorium Fitopatologi, SEAMEO BIOTROP.

\section{DAFTAR PUSTAKA}

Chen C. 2003. Evaluation of air oven moisture content determination methods for roughrice. Biosystems Engineering. 86(4):447-457. DOI:10.1016/j.biosystemseng.2003.08.010.

Davis TS, Crippen TL, Hofstetter RW, Tomberlin JK. 2013. Microbial volatile emissions as insect semiochemicals. J Chem Ecol. 39(6):687-806. DOI: 10.1007/ s10886-013-0306-z.

Flinn PW, Campbell JF. 2012. Effects of flour conditioning on cannibalism Tribolium 
castaneum eggs and pupae. Environ Entomol. 41(6):1501-1504. DOI: http:// dx.doi.org/10.1603/EN12222.

Haines CP. 1991. Insects and Arachnids of Tropical Stored products : Their Biology and Identification. Edisi ke-2. London (UK): Natural Resource Institute.

Pitt JI, Hocking AD. 2009. Fungi and Food Spoilage. New York (US) : Springer.

Prendeville HR, Stevens L. 2002. Microbe inhibition by Tribolium flour beetles varies with beetle species, strain, sex, and microbial group. J Chem Ecol. 28(6):11831190.

Sarwar M. 2013. Development and boosting of integrated insect pests management in stored grains.. Research and Reviews: J Agric Allied Sci. 2(4):16-20.
Sinha KK, Sinha AK. 1992. Impact of stored grain pests on seed deterioration and aflatoxin contamination in maize. J Stored Prod Res. 28(1):211-219.

Utomo IM. 2013. Assessment of grain loss due to insect pest during storage for smallscale farmers of Kebbi. IOSR J Agric Vet Sci. 3(5):38-50.

Wiranata RA, Himawan T, Astuti LP. 2013. Identifikasi arthropoda hama dan musuh alami pada gudang beras Perum BULOG dan gudang gabah mitra kerja di Kabupaten Jember. J HPT Tropika. 1(2):52-57.

Wicklow DT. 1995. The mycology of stored grain: an ecological perspective. Di dalam: Jayas DS et al., editor. Stored Grain Ecosystems. New York (US): Marcel Dekker, Inc. hlm 197-249. 